\title{
The Elasticity of Substitution and the Sector Bias of International Outsourcing
}

\author{
Daniel Horgos \\ Department of Economics, Helmut Schmidt University-University FAF Hamburg, Holstenhofweg 85, 22043 Hamburg, Germany \\ Correspondence should be addressed to Daniel Horgos, horgos@hsu-hh.de \\ Received 14 December 2010; Accepted 10 April 2011 \\ Academic Editor: Priya Ranjan \\ Copyright () 2011 Daniel Horgos. This is an open access article distributed under the Creative Commons Attribution License, \\ which permits unrestricted use, distribution, and reproduction in any medium, provided the original work is properly cited. \\ Considering a possible sector bias of international outsourcing within a $2 \times 2$ framework, four different scenarios appear. The \\ relative high or the relative low-skill intensive industry can relocate either its high or its low-skill intensive production fragment. \\ Traditionally, depending on the superiority of either the wage or the outsourcing effect, general equilibrium effects are regarded as \\ ambiguous in two of the four scenarios. In this contribution, I provide a formal approach and a calibration exercise for the German \\ economy. Results show that a focus on the elasticity of substitution can complete the picture. When the elasticity exceeds a critical \\ value, results are unambiguous in all four scenarios, supporting the existence of the sector bias of international outsourcing.
}

\section{Introduction}

Effects of international outsourcing have been an important issue both in economic research and political discussion for several years now. Grossman and Helpman [1] recently mentioned "we live in an age of outsourcing" (page 135). In industrialized economies, concerns arise about possibly induced labor market disruptions, harming low-skilled labor. These concerns are based on the so-called factor bias of international outsourcing, first stressed by Feenstra and Hanson [2, 3]. As Feenstra and Hanson show within a onesector model, international outsourcing in industrialized economies decreases relative demand for low-skilled labor, if it is the relative low-skill intensive production block that gets relocated. Thus, the relative wage of high-skilled labor increases. As a consequence, international outsourcing is seen as beneficial for high-skilled and harmful to lowskilled labor, inducing welfare-reducing effects in general equilibrium.

However, results differ when extending this one-sector model to more industries and, thus, when shifting the focus toward more disaggregated industry levels. As Arndt [46] shows, different effects occur depending on the relative skill intensity of the industry realizing outsourcing activities. Generally, international outsourcing decreases production costs of the respective industry and, thus, enables a wage premium if the economy faces given world prices. If international outsourcing takes place in the relative highskill intensive industry, high-skilled labor receives this wage markup. On the other hand, if international outsourcing takes place in the relative low-skill intensive industry, lowskilled labor benefits by receiving the wage premium. In general equilibrium, the outsourcing industry increases output in tandem with employment. As these results show, low-skilled labor can benefit from international outsourcing even in industrialized economies, if it takes place in the relative low-skill intensive industry. Thus, Arndt [4] concludes "concerns about the welfare-reducing implications of offshore sourcing appear to be greatly exaggerated" (page 77).

More recently, a substantial amount of theoretical contributions emerged extending these models in order to investigate different aspects of international outsourcing effects. To mention just a few of them, Deardorff $[7,8]$ illuminates the importance of the relative factor intensity of the relocated production blocks. Burda and Dluhosch [9] investigate international outsourcing within an increasing returns to scale framework to focus more on determinants arising with monopolistic competition. Egger and Falkinger [10] consider different modes of final goods production and examine several different equilibrium situations in order to determine the dominance of the factor or the sector 
bias of international outsourcing. Kohler [11] also examines distributional effects of international outsourcing. Allowing for an arbitrary number of goods, factors, and fragments, he presents a "general principle which is at force" (page 91) and provides the possibility of different parameter settings to achieve several well-known outsourcing results, i.a. those of Feenstra and Hanson as well as Arndt. More recently, Kohler [12] investigates differences between the sector bias models and models presented in the literature that meanwhile emerged on task trade, initiated by Grossman and RossiHansberg [13]. In this paper, Kohler specifically mentions the importance of offshoring heterogeneous tasks at the industry level and, thus, the sector bias of offshoring. Furthermore, he shows how the sector bias model of offshoring can be reconciled with the task trade framework of Grossman and Rossi-Hansberg.

Examining the sector bias of international outsourcing as presented by Arndt [4-6] in greater detail, four different scenarios appear: international outsourcing can occur in the relative low-skill intensive industry by relocating either its low or its high-skill intensive production fragment. The relative high-skill intensive industry can also relocate either its low or its high-skill intensive production block. In general equilibrium, each of these international outsourcing scenarios induces certain effects on relative wages, relative labor unit requirements, output, as well as employment. As Arndt carefully demonstrated, results of all four scenarios are unambiguous, regarding the effects on relative wages. However, concerning the effects on relative labor unit requirements, results become ambiguous in two of the four cases. Consequently, effects on output as well as employment are also not clear cut in these two ambiguous cases. Table 1 summarizes the general equilibrium effects of the sector bias of international outsourcing, highlighting the two ambiguous scenarios.

As the table shows, relative wages of the high-skilled increase if international outsourcing takes place in the relative high-skill intensive industry. This effect occurs if the industry relocates either its high or its low-skill intensive production fragment. By contrast, international outsourcing decreases the relative wage of the high-skilled if it takes place in the relative low-skill intensive industry. As in the relative high-skill intensive industry, this effect occurs if the industry either relocates its high or its lowskill intensive production block. The effects on relative wages induce skill shifts in both industries and, thus, affect relative labor unit requirements. Thereby, however, two of the four international outsourcing scenarios yield only ambiguous results (international outsourcing of the highskill intensive production block in the relative low-skill intensive industry and international outsourcing taking place in the relative high-skill intensive industry by relocating its low-skill intensive fragment). In general equilibrium, this ambiguity seeps through to the effects on output as well as employment. Thus, general equilibrium effects of the sector bias of international outsourcing are determined exhaustively in only two of the four possible scenarios: the relative low-skill intensive industry relocating its low-skill intensive production part and the relative high-skill intensive industry relocating its high-skill intensive one.

Most of the empirical examinations concerning outsourcing issues are based on the factor bias and not on the sector bias of international outsourcing. The fact that the theoretical framework of the sector bias has not been completely solved yet might be one reason discouraging empirical economists from further investigating these effects. But is the distinction between the four different scenarios mentioned above, and hence the sector bias of international outsourcing, really of minor importance? In order to investigate its empirical relevance, I calculated the magnitude and development of the four different international outsourcing scenarios for Germany. The results are presented in Table 2. (The calculations are based on input-output tables provided by the Federal Statistical Office in Germany and are calculated using the Vertical Specialization index, an index often used to proxy international outsourcing activities. The index relates imported intermediates (estimated) to the output of an industry. For a detailed investigation of the VS index, compared to several other international outsourcing indices, see Horgos [14].)

As the numbers show, international outsourcing activities in the two ambiguous cases are by no means less important than in the other ones. Regarding the relative low-skill intensive industries, the average of international outsourcing of the high-skill intensive parts is about one half (1991 and 1995) or two thirds (2000) of the average of relocating the low-skill intensive production blocks. Concerning the development of international outsourcing, this scenario is becoming even more important with a growth rate of around 38 percent. Thus, the two ambiguous scenarios seem to be of high empirical relevance to an overall examination of international outsourcing activities. Since to date there is no theoretical contribution providing a complete solution for all four scenarios of the sector bias of international outsourcing, this contribution tries to fill this gap.

Applying a formal model of general equilibrium effects of international outsourcing and a calibration exercise to the German economy, this paper finds that results depend strongly on the elasticity of substitution between low- and high-skilled labor. As it turns out, if the elasticities exceed a critical value, effects are no longer ambiguous and support the sector bias of international outsourcing. An increase in international outsourcing in the relative low-skill intensive industry unambiguously reduces the relative wage of the high-skilled and increases their relative labor unit requirements. As the outsourcing industry gets more productive on world markets, output as well as the employment of this industry increases. These effects occur if the industry relocates either its low or its high-skill intensive production fragment. Results are similar (with opposite direction) when international outsourcing takes place in the relative high-skill intensive industry.

The remainder of the paper is structured as follows. Section 2 discusses the model setup. The framework builds on the modern duality approach to general equilibrium and is in line with international trade contributions like Uzawa [15], Diewert [16, 17], Woodland [18], and Mussa 
TABLE 1: Sector bias of international outsourcing (overview).

\begin{tabular}{|c|c|c|c|c|}
\hline \multirow{2}{*}{ Scenario } & \multicolumn{2}{|c|}{ Low-skill intensive Industry } & \multicolumn{2}{|c|}{ High-skill intensive Industry } \\
\hline & Low-skill part & High-skill part & Low-skill part & High-skill part \\
\hline $\begin{array}{l}\text { Relative wages of the } \\
\text { high-skilled }\end{array}$ & $\downarrow$ & $\downarrow$ & $\uparrow$ & $\uparrow$ \\
\hline $\begin{array}{l}\text { Relative labor unit } \\
\text { requirements of the } \\
\text { high-skilled }\end{array}$ & $\uparrow$ & $?$ & $?$ & $\downarrow$ \\
\hline \multirow[t]{2}{*}{ Output } & $\begin{array}{l}\text { High-skill intensive } \\
\text { Industry } \downarrow\end{array}$ & $?$ & $?$ & $\begin{array}{l}\text { High-skill intensive } \\
\text { Industry } \uparrow\end{array}$ \\
\hline & $\begin{array}{l}\text { Low-skill intensive } \\
\text { Industry } \uparrow\end{array}$ & & & $\begin{array}{l}\text { Low-skill intensive } \\
\text { Industry } \downarrow\end{array}$ \\
\hline \multirow[t]{2}{*}{ Employment } & $\begin{array}{l}\text { High-skill intensive } \\
\text { Industry } \downarrow\end{array}$ & $?$ & $?$ & $\begin{array}{l}\text { High-skill intensive } \\
\text { Industry } \uparrow\end{array}$ \\
\hline & $\begin{array}{l}\text { Low-skill intensive } \\
\text { Industry } \uparrow\end{array}$ & & & $\begin{array}{c}\text { Low-skill intensive } \\
\text { Industry } \downarrow\end{array}$ \\
\hline
\end{tabular}

TABLE 2: Magnitude and development of international outsourcing in Germany.

\begin{tabular}{lcccc}
\hline \multirow{2}{*}{ Scenario } & \multicolumn{2}{c}{ low-skill intensive industries } & \multicolumn{2}{c}{ High-skill intensive industries } \\
& Low-skill parts (\%) & High-skill parts (\%) & Low-skill parts (\%) & High-skill parts (\%) \\
\hline 1991 & 6 & 3 & 2 & 8 \\
1995 & 6 & 3 & 2 & 9 \\
2000 & 6 & 4 & 2 & 12 \\
\hline $1991-2000$ & 7 & 38 & 0 & 59 \\
\hline
\end{tabular}

[19]. International outsourcing is introduced similar to skill-biased technical progress as in Jones [20]. Section 3 examines general equilibrium effects of the four international outsourcing scenarios, shifting the focus especially on the importance of the elasticity of substitution. As the elasticities exceed a critical value, effects on relative labor unit requirements are no longer ambiguous and driven by the relative skill intensity of the industry fragmenting production. However, since effects on output and employment are only clear-cut with the assumption of Cobb Douglas elasticities, Section 4 calibrates the model for a wider range of elasticities using data for the German economy in 2005. Section 5 concludes by summarizing the major findings.

\section{Model SetUp}

In order to investigate general equilibrium effects of international outsourcing, this paper uses the modern duality approach, based on Shephard's Lemma, and is in line with international trade contributions as Uzawa [15], Diewert [16, 17], Woodland [18], or Mussa [19]. The duality approach in international trade formulates equilibrium conditions in terms of unit cost functions rather than production functions and minimizes these unit costs in a factor price space. (Traditional trade theory, by contrast, analyzes equilibrium conditions within a quantity space as introduced by Lerner [21] and made popular by Chipman [22]. The decision to choose the duality approach in this paper can be attributed to several advantages with respect to Shephard's Lemma that will be explained below.)

Assume an economy that faces given world prices $p$ with two industries, a relative high-skill intensive $(X)$ and a relative low-skill intensive one $(Y)$. (By assuming that the economy's trade flows do not affect the price $(\hat{p}=0)$ and the price elasticity of demand being unity $\left(\sigma^{D}=1\right)$, we ensure that the world market is able to absorb changes in demand. Thus, while setting the focus on the supply side, we are able to abstract from price changes and their effects on the production structure of the two industries.) Both industries use two primary inputs, low-skilled labor $(L)$ and high-skilled labor $(H)$ to produce goods of quantity $q_{i}$ (with $i=X, Y$ ). Factors are mobile between industries, but internationally immobile. The home economy faces an inelastic supply of factors $(\bar{L}, \bar{H})$ and remains incompletely specialized $\left(q_{i}>0\right)$ throughout the process. Thus, with goods as well as factor markets perfectly competitive, we achieve

$$
\begin{aligned}
& c_{Y}=a_{Y L} w_{L}+a_{Y H} w_{H}=1, \\
& c_{X}=a_{X L} w_{L}+a_{X H} w_{H}=p
\end{aligned}
$$

with $c_{i}$ as unit costs per industry equaling the price, $a_{i j}$ as unit factor requirements $(j=L, H), w_{j}$ as factor prices and the price of the low-skill intensive good $(Y)$ as numeraire. The unit cost functions are positive and linearly homogeneous. According to Shephard's lemma, we 
can partially differentiate the unit cost functions to solve for the cost-minimizing labor unit requirements

$$
\begin{aligned}
& a_{Y L}=\frac{\partial c_{Y}\left(w_{L}, w_{H}\right)}{\partial w_{L}}, \\
& a_{Y H}=\frac{\partial c_{Y}\left(w_{L}, w_{H}\right)}{\partial w_{H}}, \\
& a_{X L}=\frac{\partial c_{X}\left(w_{L}, w_{H}\right)}{\partial w_{L}}, \\
& a_{X H}=\frac{\partial c_{X}\left(w_{L}, w_{H}\right)}{\partial w_{H}} .
\end{aligned}
$$

Due to flexible wages, each factor is either employed in the $X$ or in the $Y$ industry. Thus, we achieve

$$
\begin{aligned}
& \bar{L}=a_{Y L} q_{Y}+a_{X L} q_{X}, \\
& \bar{H}=a_{Y H} q_{Y}+a_{X H} q_{X}
\end{aligned}
$$

as the labor market clearing conditions and have a system of eight endogenous variables $\left(w_{H}, w_{L}, a_{X L}, a_{X H}, a_{Y L}, a_{Y H}, q_{X}\right.$, and $\left.q_{Y}\right)$ in eight equations (1)-(8) that exactly determine the model.

To introduce international outsourcing, we extend the framework by an international outsourcing parameter $\varphi_{i j}$. Similar to skill-biased technical change as in Jones [20], we define the percentage change of $\varphi$ as $\hat{\varphi}_{i j} \equiv-1 / a_{i j}$. $\left(\partial a_{i j} / \partial I O_{i j}\right)$, showing the alteration in $a_{i j}$ due to international outsourcing $(I O)$ that would take place at constant wages. Since international outsourcing is assumed to reduce labor unit requirements $\left(\partial a_{i j} / \partial I O_{i j}<0\right), \hat{\varphi}>0$ if international outsourcing activities take place. In this form, international outsourcing is an exogenous process directly affecting labor unit requirements. (In order to focus on the effects of international outsourcing, and to keep the model traceable, determinants of international outsourcing are not considered explicitly.)

We are now able to rewrite the unit cost functions (1) and (2) into

$$
\begin{aligned}
& c_{Y}\left(\vec{w}_{L}, \vec{w}_{H}\right)=\vec{a}_{Y L} \vec{w}_{L}+\vec{a}_{Y H} \vec{w}_{H}, \\
& c_{X}\left(\vec{w}_{L}, \vec{w}_{H}\right)=\vec{a}_{X L} \vec{w}_{L}+\vec{a}_{X H} \vec{w}_{H}
\end{aligned}
$$

with $\vec{w}_{j} \equiv w_{j} / \varphi_{i j}$ and $\vec{a}_{i j} \equiv \varphi_{i j} a_{i j}$ as wages and labor unit requirements considering international outsourcing activities. Thus, ceteris paribus, if international outsourcing takes place $(\hat{\varphi}>0)$, the respective wages $w_{j}$ increase, whereas the respective labor unit requirements $a_{i j}$ decrease. These effects are described in greater detail when investigating general equilibrium effects of international outsourcing in the next section.

It is important to mention that the way of formally modeling international outsourcing here is the same way in which Arndt [4-6] illustrates international outsourcing graphically. Nevertheless, as will be discussed in greater detail in the following sections, the way of modeling international outsourcing here differs strongly from the wellknown frameworks examining technological change. While technological change is analyzed either with a sector or a factor bias (biased with respect to one industry or one sector: two different scenarios), it is of great importance to focus on all four possible scenarios when considering outsourcing activities (one industry can either outsource its low or its high-skill intensive part of production, four different scenarios). As we will see below, due to this extension of possibilities, results differ from the well-known patterns of technical progress.

\section{General Equilibrium Effects of International Outsourcing}

To investigate general equilibrium effects of international outsourcing, this section first examines the change in relative wages. Afterward, the effects on relative labor unit requirements, output as well as employment are considered.

3.1. Relative Wages. In order to minimize costs, we totally differentiate the unit cost functions (9) and achieve

$$
\begin{aligned}
& \theta_{Y L} \hat{w}_{L}+\theta_{Y H} \widehat{w}_{H}=\theta_{Y L} \hat{\varphi}_{Y L}+\theta_{Y H} \hat{\varphi}_{Y H}, \\
& \theta_{X L} \hat{w}_{L}+\theta_{X H} \hat{w}_{H}=\theta_{X L} \hat{\varphi}_{X L}+\theta_{X H} \hat{\varphi}_{X H}
\end{aligned}
$$

as equilibrium production costs in both industries with factor income shares $\theta_{i j} \equiv a_{i j} w_{j} / p_{i}$ and "hat" denoting percentage changes. Equation (10) directly distinguish between the four different international outsourcing scenarios already mentioned in the introduction:

(i) international outsourcing of the low-skill intensive production part in the relative low-skill intensive industry $\left(\hat{\varphi}_{Y L}>0\right.$ whereas $\left.\hat{\varphi}_{Y H}=\hat{\varphi}_{X L}=\hat{\varphi}_{X H}=0\right)$,

(ii) international outsourcing of the high-skill intensive production part in the relative low-skill intensive industry $\left(\hat{\varphi}_{Y H}>0\right.$ whereas $\left.\hat{\varphi}_{Y L}=\widehat{\varphi}_{X L}=\hat{\varphi}_{X H}=0\right)$,

(iii) international outsourcing of the low-skill intensive production part in the relative high-skill intensive industry $\left(\hat{\varphi}_{X L}>0\right.$ whereas $\left.\hat{\varphi}_{Y L}=\hat{\varphi}_{Y H}=\hat{\varphi}_{X H}=0\right)$,

(iv) international outsourcing of the high-skill intensive production part in the relative high-skill intensive industry $\left(\hat{\varphi}_{X H}>0\right.$ whereas $\left.\hat{\varphi}_{Y L}=\hat{\varphi}_{Y H}=\hat{\varphi}_{X L}=0\right)$.

Assuming scenario (i) first, (10) can be solved for the effects of international outsourcing on the percentage change in real wages

$$
\begin{aligned}
\left.\hat{w}_{L}\right|_{\hat{\varphi}_{Y L}>0} & =\frac{\theta_{X H} \theta_{Y L}}{\Delta_{\Theta}} \hat{\varphi}_{Y L}, \\
\left.\widehat{w}_{H}\right|_{\hat{\varphi}_{Y L}>0} & =-\frac{\theta_{X L} \theta_{Y L}}{\Delta_{\Theta}} \hat{\varphi}_{Y L}
\end{aligned}
$$

with the determinant $\Delta_{\Theta} \equiv\left|\begin{array}{cc}\theta_{X H} & \theta_{X L} \\ \theta_{Y H} & \theta_{Y L}\end{array}\right|>0$. Since the factor income shares are positive per definition $\left(\theta_{i j}>0\right)$, lowskilled real wages increase $(13>0)$, whereas wages of the high-skilled decrease $(14<0)$. As we know from the sector bias, international outsourcing reduces the production costs 


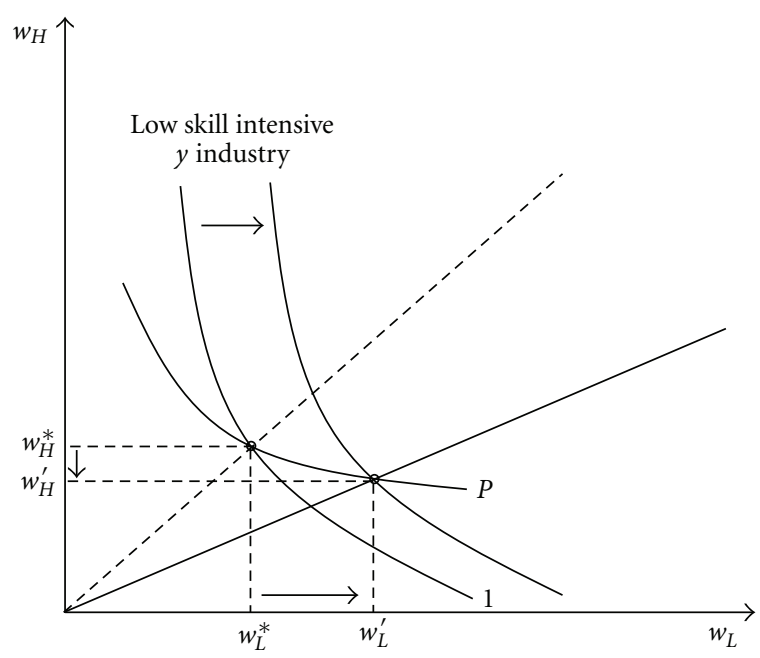

FIGURE 1: Effects of international outsourcing on wages.

of the respective industry and, thus, since we assume an economy facing given world prices, it enables a wage premium for either high or low-skilled labor. Since international outsourcing takes place in the relative low-skill intensive industry in this scenario, low-skilled labor receives the wage premium, while wages of the high-skilled decrease. Equation (11) can be rearranged in order to achieve

$$
\widehat{w}_{H}-\left.\widehat{w}_{L}\right|_{\hat{\varphi}_{Y L}>0}=-\frac{\theta_{Y L}}{\Delta_{\Theta}} \hat{\varphi}_{Y L}
$$

as the percentage change of the relative wage of high-skilled labor. Figure 1 illustrates this process within a factor-price space.

If international outsourcing takes place in the relative low-skill intensive industry by relocating the low-skill intensive production block, the industry needs less lowskilled workers to produce one unit of commodity $Y$ (since outsourcing directly reduces labor unit requirements). As the economy is assumed to be small and, thus, faces given world prices, unit costs of this industry decrease. As can be seen in the figure, the unit cost curve of the $y$ industry shifts horizontally outward. Since the relative price of $Y$ has remained unchanged, the cost reduction leads producers to increase output. Thus, they will raise relative demand for low-skilled labor (since the industry is relative lowskill intensive). Therefore, relative wages of the low-skilled increase.

Assuming scenario (ii), wage effects are of the same tendency since international outsourcing occurs in the same industry. Real wages of the high-skilled decrease, while lowskilled labor again receives the wage premium. Thus, relative wages of the high skilled decrease with

$$
\widehat{w}_{H}-\left.\widehat{w}_{L}\right|_{\hat{\varphi}_{Y H}>0}=-\frac{\theta_{Y H}}{\Delta_{\Theta}} \hat{\varphi}_{Y H} .
$$

Since, in the relative low-skill intensive industry, the factor income shares of the low-skilled are bigger than the factor income shares of the high skilled $\left(\theta_{Y L}>\theta_{Y H}\right)$, the decrease in relative wages of the high skilled is bigger if the industry relocates its low-skill intensive production patterns $\left(\widehat{w}_{H}-\left.\widehat{w}_{L}\right|_{\hat{\varphi}_{Y L}>0}<\widehat{w}_{H}-\left.\widehat{w}_{L}\right|_{\hat{\varphi}_{Y H}>0}\right)$.

Considering international outsourcing (to take place) in the relative high-skill intensive industry, scenarios (iii) and (iv), results have the opposite direction. For the percentage change in relative high skilled wages, we achieve

$$
\begin{aligned}
& \widehat{w}_{H}-\left.\widehat{w}_{L}\right|_{\hat{\varphi}_{X L}>0}=\frac{\theta_{X L}}{\Delta_{\Theta}} \hat{\varphi}_{X L}, \\
& \widehat{w}_{H}-\left.\widehat{w}_{L}\right|_{\hat{\varphi}_{X H}>0}=\frac{\theta_{X H}}{\Delta_{\Theta}} \hat{\varphi}_{X H}
\end{aligned}
$$

with both effects being positive and $\widehat{w}_{H}-\left.\widehat{w}_{L}\right|_{\hat{\varphi}_{X H}>0}>$ $\widehat{w}_{H}-\left.\widehat{w}_{L}\right|_{\hat{\varphi}_{X L}>0}$. Proposition 3.1 summarizes the effects of international outsourcing on relative wages, considering the four different international outsourcing scenarios.

Proposition 3.1. The relative wage of high-skilled labor decreases if international outsourcing takes place in the relative low-skill intensive industry. If international outsourcing takes place in the relative high-skill intensive industry, relative highskilled wages increase. This pattern occurs regardless of which production block of the respective industry gets relocated.

3.2. Relative Labor Unit Requirements. As we know from Shephard's Lemma, equilibrium labor unit requirements can be achieved by partially differentiating the unit cost functions (see (3)-(6)). With log differentiation, we obtain

$$
\begin{gathered}
\hat{a}_{Y L}=\theta_{Y H} \sigma^{Y}\left(\hat{w}_{H}-\hat{w}_{L}+\hat{\varphi}_{Y L}-\hat{\varphi}_{Y H}\right)-\hat{\varphi}_{Y L}, \\
\hat{a}_{Y H}=-\theta_{Y L} \sigma^{Y}\left(\hat{w}_{H}-\hat{w}_{L}+\hat{\varphi}_{Y L}-\hat{\varphi}_{Y H}\right)-\hat{\varphi}_{Y H}, \\
\hat{a}_{X L}=\theta_{X H} \sigma^{X}\left(\hat{w}_{H}-\hat{w}_{L}+\hat{\varphi}_{X L}-\hat{\varphi}_{X H}\right)-\hat{\varphi}_{X L}, \\
\hat{a}_{X H}=-\theta_{X L} \sigma^{X}\left(\hat{w}_{H}-\hat{w}_{L}+\hat{\varphi}_{X L}-\hat{\varphi}_{X H}\right)-\hat{\varphi}_{X H}
\end{gathered}
$$

as the percentage change of labor unit requirements with $\sigma^{i}$ as elasticity of substitution between low and high-skilled labor in industry $i(i=X, Y)$. Now, assume again scenario (i: $\left.\hat{\varphi}_{Y L}>0\right)$ and substitute for the percentage change of low and high-skilled real wages, which yields

$$
\begin{gathered}
\hat{a}_{Y H}-\left.\hat{a}_{Y L}\right|_{\hat{\varphi}_{Y L}>0}=\sigma^{Y} \frac{\theta_{Y L}}{\Delta_{\Theta}} \hat{\varphi}_{Y L}+\left(1-\sigma^{Y}\right) \hat{\varphi}_{Y L}, \\
\hat{a}_{X H}-\left.\hat{a}_{X L}\right|_{\hat{\varphi}_{Y L}>0}=\sigma^{X} \frac{\theta_{Y L}}{\Delta_{\Theta}} \hat{\varphi}_{Y L},
\end{gathered}
$$

as the percentage change of relative labor unit requirements of the high-skilled in the two industries. In the relative highskill intensive industry $(X)$, the industry that holds on to its integrated production process in this scenario, relative labor unit requirements increase solely due to the wage effect. Since relative wages of the high-skilled decrease in both industries (see (12)), the industries substitute high for low-skilled labor. By contrast, in the relative low-skill intensive industry $(Y)$, the industry performing international outsourcing activities, the wage effect is accompanied by an outsourcing effect. 
Since the industry relocates its low-skill intensive production fragment, additional effects occur for relative labor unit requirements. Depending on the elasticity of substitution between low and high skilled labor, the outsourcing effect can either increase (if $0<\sigma^{Y}<1$ ) or reduce relative labor unit requirements of the high-skilled (if $\sigma^{Y}>1$ ). With Cobb Douglas elasticities $\left(\sigma^{i}=1\right)$, the outsourcing effect equally decreases low and high skilled labor unit requirements. However, in the ongoing scenario (i) the wage effect outperforms the outsourcing effect in any case, since $\theta_{Y L} / \Delta_{\Theta}>1$. Thus, as illustrated in Arndt [4], relative labor unit requirements of the high-skilled unambiguously increase in both industries, inducing a skill shift toward more high-skilled labor.

Considering the first ambiguous case (scenario ii: $\hat{\varphi}_{Y H}>$ $0)$, we achieve

$$
\begin{gathered}
\hat{a}_{Y H}-\left.\hat{a}_{Y L}\right|_{\hat{\varphi}_{Y H}>0}=\sigma^{Y} \frac{\theta_{Y H}}{\Delta_{\Theta}} \hat{\varphi}_{Y H}-\left(1-\sigma^{Y}\right) \hat{\varphi}_{Y H}, \\
\hat{a}_{X H}-\left.\hat{a}_{X L}\right|_{\hat{\varphi}_{Y H}>0}=\sigma^{X} \frac{\theta_{Y H}}{\Delta_{\Theta}} \hat{\varphi}_{Y H}
\end{gathered}
$$

as the effects of international outsourcing on relative labor unit requirements of the high skilled. In the relative high skill intensive industry $(X)$, in which the production process still remains integrated, relative labor unit requirements of the high skilled increase again solely due to the wage effect. In the relative low-skill intensive industry $(Y)$, the wage effect is again accompanied by an outsourcing effect. In this scenario, when relocating the high-skill intensive fragment, the wage effect is not as strong as in scenario (i), providing the possibility for the outsourcing effect to outperform the wage effect. However, with the elasticity of substitution being big enough, the wage effect is still dominant, leading to an increase in relative labor unit requirements of the highskilled $\left(\hat{a}_{Y H}-\left.\hat{a}_{Y L}\right|_{\hat{\varphi}_{Y H}>0}>0\right.$ if $\left.\sigma^{Y}>\Delta_{\Theta} / \theta_{X H}\right)$. By contrast, if the elasticity of substitution is beneath this critical value, the wage effect still increases relative labor unit requirements of the high-skilled. However, the outsourcing effect is stronger and, thus, the change of relative high-skilled labor unit requirements turns negative. With regard to the critical value of the elasticity in detail, we can note that $0<\Delta_{\Theta} / \theta_{X H}<$ 1 since $\Delta_{\Theta}<\theta_{X H}$ per definition. Thus, assuming Cobb Douglas elasticities, the wage effect is always stronger than the outsourcing effect. International outsourcing, therefore, increases relative labor unit requirements of the high skilled, as in the first scenario (i).

A similar result occurs when considering the second ambiguous case (scenario iii: $\hat{\varphi}_{X L}>0$ ). Since the relative high-skill intensive industry relocates its low-skill intensive production block, the change in relative labor unit requirements of the high-skilled can be described with

$$
\begin{gathered}
\hat{a}_{Y H}-\left.\hat{a}_{Y L}\right|_{\hat{\varphi}_{X L}>0}=-\sigma^{Y} \frac{\theta_{X L}}{\Delta \Theta} \hat{\varphi}_{X L}, \\
\hat{a}_{X H}-\left.\hat{a}_{X L}\right|_{\hat{\varphi}_{X L}>0}=-\sigma^{X} \frac{\theta_{X L}}{\Delta_{\Theta}} \hat{\varphi}_{X L}+\left(1-\sigma^{X}\right) \hat{\varphi}_{X L},
\end{gathered}
$$

whereby in the relative high-skill intensive industry $(X)$, it depends on the elasticity of substitution $\left(\sigma^{X}\right)$ whether the wage effect outperforms the outsourcing effect, or vice versa. As can be shown, $\hat{a}_{X H}-\left.\hat{a}_{X L}\right|_{\hat{\varphi}_{X L}>0}<0$ if $\sigma^{X}>\Delta_{\Theta} / \theta_{Y L}$. Thus, with the elasticity of substitution being big enough, the wage effect outperforms the outsourcing effect again, leading to a reduction of relative labor unit requirements of the highskilled. Since $\theta_{Y L}>\Delta_{\Theta}$ per definition, $0<\Delta_{\Theta} / \theta_{Y L}<1$ indicating that within a Cobb Douglas world, international outsourcing always decreases relative labor unit requirements of the high-skilled due to the dominance of the wage effect.

One scenario is still missing: international outsourcing of the high-skill intensive production block in the relative high-skill intensive industry (scenario iv: $\hat{\varphi}_{X H}>0$ ). There, we achieve

$$
\begin{gathered}
\hat{a}_{Y H}-\left.\hat{a}_{Y L}\right|_{\hat{\varphi}_{X H}>0}=-\sigma^{Y} \frac{\theta_{X H}}{\Delta_{\Theta}} \hat{\varphi}_{X H}, \\
\hat{a}_{X H}-\left.\hat{a}_{X L}\right|_{\hat{\varphi}_{X H}>0}=-\sigma^{X} \frac{\theta_{X H}}{\Delta_{\Theta}} \hat{\varphi}_{X H}-\left(1-\sigma^{X}\right) \hat{\varphi}_{X H}
\end{gathered}
$$

as the percentage change in relative labor unit requirements of the high skilled. If $\theta_{X H} / \Delta_{\Theta}>1$, results are unambiguous with the wage effect outperforming the outsourcing effect in any case, as in scenario (i). Thus, with the relative wage of the high-skilled increasing (see (18)), an unambiguous skill shift toward more low-skilled labor occurs in both industries. Proposition 3.2 summarizes the results of this section.

Proposition 3.2. The effects of international outsourcing on relative labor unit requirements of the high-skilled are driven by a wage and an outsourcing effect. While results are unambiguous in two of the four possible scenarios, the outsourcing effect can outperform the wage effect in the remaining two scenarios, leading to ambiguous results. The elasticity of substitution between low and high-skilled labor is the parameter solving this ambiguity. If the elasticity exceeds a critical value, the wage effect is stronger than the outsourcing effect, leading to unambiguous results that substantiate the sector bias of international outsourcing. Relative labor unit requirements of the high skilled increase if international outsourcing takes place in the relative low-skill intensive industry and decrease if it takes place in the relative high-skill intensive industry. Which production block gets relocated is only of minor importance.

3.3. Output. In order to examine the effects of international outsourcing on the output of the industries, remember the full employment conditions (7) and (8), take the total differential, and substitute for the change in relative wages and relative labor unit requirements. For scenario (i: $\hat{\varphi}_{Y L}>$ $0)$, we achieve

$$
\begin{aligned}
\left.\hat{q}_{Y}\right|_{\hat{\varphi}_{Y L}>0}= & \frac{\left(\delta_{H} \lambda_{X L}+\delta_{L} \lambda_{X H}\right)}{\Delta_{\Theta} \Delta_{\Lambda}} \theta_{Y L} \hat{\varphi}_{Y L} \\
& +\frac{\left(1-\sigma^{Y}\right) \lambda_{X H} \lambda_{Y L}}{\Delta_{\Lambda}} \hat{\varphi}_{Y L}+\sigma^{Y} \theta_{Y L} \hat{\varphi}_{Y L}, \\
\left.\hat{q}_{X}\right|_{\hat{\varphi}_{Y L}>0}= & -\frac{\left(\delta_{H} \lambda_{Y L}+\delta_{L} \lambda_{Y H}\right)}{\Delta_{\Theta} \Delta_{\Lambda}} \theta_{Y L} \hat{\varphi}_{Y L} \\
& -\frac{\left(1-\sigma^{Y}\right) \lambda_{Y H} \lambda_{Y L}}{\Delta_{\Lambda}} \hat{\varphi}_{Y L}
\end{aligned}
$$


as the percentage change of the industries' output with $\lambda$ as labor shares $\left(\lambda_{i j}=L_{i} / L\right.$, or $H_{i} / H$, resp. $), \delta_{L} \equiv \lambda_{X L} \theta_{X H} \sigma^{X}+$ $\lambda_{Y L} \theta_{Y H} \sigma^{Y}$, and $\delta_{H} \equiv \lambda_{X H} \theta_{X L} \sigma^{X}+\lambda_{Y H} \theta_{Y L} \sigma^{Y}$. With respect to output, results depend on too many parameters for getting solved endogenously. The $\theta$ 's and $\lambda$ 's are implicitly driven by low and high-skilled wages, the four labor unit requirements, labor endowments in both industries, and the two elasticities of substitution. Thus, in order to achieve a closed-form solution and to extract the relative effects on output, we need to assume Cobb Douglas elasticities at first. (We relax the Cobb Douglas assumption of this paragraph in the calibration exercise in Section 4.) With these assumptions, we are able to reduce equations (20) and (32) to

$$
\begin{gathered}
\left.\hat{q}_{Y}\right|_{\hat{\varphi}_{Y L}>0}=\frac{\left(\delta_{H} \lambda_{X L}+\delta_{L} \lambda_{X H}\right)}{\Delta_{\Theta} \Delta_{\Lambda}} \theta_{Y L} \hat{\varphi}_{Y L}+\theta_{Y L} \hat{\varphi}_{Y L}, \\
\left.\hat{q}_{X}\right|_{\hat{\varphi}_{Y L}>0}=-\frac{\left(\delta_{H} \lambda_{Y L}+\delta_{L} \lambda_{Y H}\right)}{\Delta_{\Theta} \Delta_{\Lambda}} \theta_{Y L} \hat{\varphi}_{Y L},
\end{gathered}
$$

with the $\delta$ 's $>0$, the $\lambda$ 's $>0$, as well as the two determinants $\Delta_{\Theta}>0$ and $\Delta_{\Lambda}>0$. As the result shows, the relative low-skill intensive industry $(Y)$, in which international outsourcing takes place in this scenario, expands output, whereas the relative high-skill intensive industry $(X)$, in which production remains integrated, reduces output.

Holding on to the Cobb Douglas assumption, even in the cases in which the effects on output are traditionally assumed to be ambiguous, unambiguous results can be obtained. When the low-skill intensive industry relocates its high-skill intensive production fragment (scenario ii: $\hat{\varphi}_{Y H}>0$ ), we achieve

$$
\begin{gathered}
\left.\hat{q}_{Y}\right|_{\hat{\varphi}_{Y H}>0}=\frac{\left(\delta_{H} \lambda_{X L}+\delta_{L} \lambda_{X H}\right)}{\Delta_{\Theta} \Delta_{\Lambda}} \theta_{Y H} \hat{\varphi}_{Y H}+\theta_{Y H} \hat{\varphi}_{Y H}, \\
\left.\hat{q}_{X}\right|_{\hat{\varphi}_{Y H}>0}=-\frac{\left(\delta_{H} \lambda_{Y L}+\delta_{L} \lambda_{Y H}\right)}{\Delta_{\Theta} \Delta_{\Lambda}} \theta_{Y H} \hat{\varphi}_{Y H}, \\
\left.\hat{q}_{Y}\right|_{\hat{\varphi}_{X L}>0}=-\frac{\left(\delta_{H} \lambda_{X L}+\delta_{L} \lambda_{X H}\right)}{\Delta_{\Theta} \Delta_{\Lambda}} \theta_{X L} \hat{\varphi}_{X L}, \\
\left.\hat{q}_{X}\right|_{\hat{\varphi}_{X L}>0}=\frac{\left(\delta_{H} \lambda_{Y L}+\delta_{L} \lambda_{Y H}\right)}{\Delta_{\Theta} \Delta_{\Lambda}} \theta_{X L} \hat{\varphi}_{X L}+\theta_{X L} \hat{\varphi}_{X L}
\end{gathered}
$$

if international outsourcing takes place in the relative highskill intensive industry by relocating its low-skill intensive production block (scenario iii: $\hat{\varphi}_{X L}>0$ ). As the results show, the industry relocating production unambiguously increases output in these two cases as well.

Turning to scenario (iv), we achieve

$$
\begin{gathered}
\left.\hat{q}_{Y}\right|_{\hat{\varphi}_{X H}>0}=-\frac{\left(\delta_{H} \lambda_{X L}+\delta_{L} \lambda_{X H}\right)}{\Delta_{\Theta} \Delta_{\Lambda}} \theta_{X H} \hat{\varphi}_{X H}, \\
\left.\hat{q}_{X}\right|_{\hat{\varphi}_{X H}>0}=\frac{\left(\delta_{H} \lambda_{Y L}+\delta_{L} \lambda_{Y H}\right)}{\Delta_{\Theta} \Delta_{\Lambda}} \theta_{X H} \hat{\varphi}_{X H}+\theta_{X H} \hat{\varphi}_{X H} .
\end{gathered}
$$

Again, the relative high-skill intensive industry $(X)$, in which international outsourcing takes place, expands while the relative low-skill intensive industry decreases output. Proposition 3.3 summarizes the effects of international outsourcing on the output of the industries.
Proposition 3.3. Regarding the effects of international outsourcing on the output of the industries, results again depend strongly on the elasticities of substitution. With Cobb Douglas elasticities, the effects are unambiguous for all four international outsourcing scenarios. The industry in which international outsourcing takes place expands, while the industry remaining integrated reduces output. This result occurs regardless of whether the industries relocate their high-or their low-skill intensive production fragment.

3.4. Employment. Since we assume a flexible wage economy, the effects of international outsourcing on employment are straightforward. Low- as well as high-skilled labor are fully employed, either in the relative low-, or in the relative highskill intensive industry. With an overall fixed supply of labor, changes of employment are in line with the contraction and expansion of the two industries. In order to achieve percentage changes of the different employment constellations within industries, consider the full employment conditions (7) and (8) and log differentiate. Substituting for the change in relative wages, relative labor unit requirements and output, and holding on to the Cobb Douglas assumption again, we achieve

$$
\begin{gathered}
\left.\hat{L}_{X}\right|_{\hat{\varphi}_{Y L}>0}=-\frac{\theta_{X H} \theta_{Y L}}{\Delta_{\Theta}} \hat{\varphi}_{Y L}-\frac{\left(\delta_{H} \lambda_{Y L}+\delta_{L} \lambda_{Y H}\right)}{\Delta_{\Theta} \Delta_{\Lambda}} \theta_{Y L} \hat{\varphi}_{Y L}, \\
\left.\hat{L}_{Y}\right|_{\hat{\varphi}_{Y L}>0}=-\frac{\theta_{Y H} \theta_{Y L}}{\Delta_{\Theta}} \hat{\varphi}_{Y L}+\frac{\left(\delta_{H} \lambda_{X L}+\delta_{L} \lambda_{X H}\right)}{\Delta_{\Theta} \Delta_{\Lambda}} \theta_{Y L} \hat{\varphi}_{Y L}, \\
\left.\hat{H}_{X}\right|_{\hat{\varphi}_{Y L}>0}=\frac{\theta_{X L} \theta_{Y L}}{\Delta_{\Theta}} \hat{\varphi}_{Y L}-\frac{\left(\delta_{H} \lambda_{Y L}+\delta_{L} \lambda_{Y H}\right)}{\Delta_{\Theta} \Delta_{\Lambda}} \theta_{Y L} \hat{\varphi}_{Y L}, \\
\left.\hat{H}_{Y}\right|_{\hat{\varphi}_{Y L}>0}=\frac{\theta_{Y L} \theta_{Y L}}{\Delta_{\Theta}} \hat{\varphi}_{Y L}+\frac{\left(\delta_{H} \lambda_{X L}+\delta_{L} \lambda_{X H}\right)}{\Delta_{\Theta} \Delta_{\Lambda}} \theta_{Y L} \hat{\varphi}_{Y L}
\end{gathered}
$$

as the percentage change of high and low-skilled labor in the two industries, if international outsourcing occurs in the relative low-skill intensive industry by relocating the low-skill intensive production block (scenario i: $\hat{\varphi}_{Y L}>0$ ). The first part of the equations is due to the change in relative wages. As the relative wage of the low-skilled increases in this scenario, the employment of the low skilled is reduced. The second component is due to the change in output of the industries (including the change in relative labor unit requirements and relative wages as well). Low and high-skilled employment expands in the industry in which international outsourcing takes place $(Y)$, since this industry increases output. As these results show, the relative high-skill intensive industry decreases the employment of the low-skilled $\left(\left.\widehat{L}_{X}\right|_{\hat{\varphi}_{Y L}>0}<0\right)$. Thus, due to the flexible wage setup, the "freed" low-skilled move to the low-skill intensive industry $(Y)$, the industry performing outsourcing activities and expanding output, to find employment. Thus, $\left.\widehat{L}_{Y}\right|_{\hat{\varphi}_{Y L}>0}$ needs to be positive. Simultaneously, the relative low-skill intensive industry $(Y)$ increases high skill intensive employment $\left(\left.\hat{H}_{Y}\right|_{\hat{\varphi}_{Y L}>0}>0\right)$. As long as we assume an inelastic supply of labor, the highskilled are withdrawn from the relative high-skill intensive industry. Thus, $\left.\hat{H}_{X}\right|_{\hat{\varphi}_{Y L}>0}$ needs to be negative. 
TABLE 3: Percentage change of relative high-skilled wages.

\begin{tabular}{ll}
\hline $\begin{array}{l}\text { International outsourcing } \\
\text { scenario }\end{array}$ & $\begin{array}{l}\text { Percentage change in relative } \\
\text { high-skilled wages }\end{array}$ \\
\hline$\hat{\varphi}_{Y L}>0$ & $\widehat{w}_{H}-\widehat{w}_{L}=-2.03$ \\
$\hat{\varphi}_{Y H}>0$ & $\widehat{w}_{H}-\widehat{w}_{L}=-.65$ \\
$\hat{\varphi}_{X L}>0$ & $\widehat{w}_{H}-\widehat{w}_{L}=1.03$ \\
$\hat{\varphi}_{X H}>0$ & $\widehat{w}_{H}-\widehat{w}_{L}=1.65$ \\
\hline
\end{tabular}

As in the previous section on output, effects on employment are unambiguous in all four scenarios since Cobb Douglas elasticities are assumed. Consider for example, scenario (ii: $\hat{\varphi}_{Y H}>0$ ), international outsourcing taking place in the relative low-skill intensive industry by relocating its high-skill intensive production fragment, we obtain

$$
\begin{gathered}
\left.\hat{L}_{X}\right|_{\hat{\varphi}_{Y H}>0}=-\frac{\theta_{X H} \theta_{Y H}}{\Delta_{\Theta}} \hat{\varphi}_{Y H}-\frac{\left(\delta_{H} \lambda_{Y L}+\delta_{L} \lambda_{Y H}\right)}{\Delta_{\Theta} \Delta_{\Lambda}} \theta_{Y H} \hat{\varphi}_{Y H}, \\
\left.\hat{L}_{Y}\right|_{\hat{\varphi}_{Y H}>0}=-\frac{\theta_{Y H} \theta_{Y H}}{\Delta_{\Theta}} \hat{\varphi}_{Y H}+\frac{\left(\delta_{H} \lambda_{X L}+\delta_{L} \lambda_{X H}\right)}{\Delta_{\Theta} \Delta_{\Lambda}} \theta_{Y H} \hat{\varphi}_{Y H}, \\
\left.\hat{H}_{X}\right|_{\hat{\varphi}_{Y H}>0}=\frac{\theta_{X L} \theta_{Y H}}{\Delta_{\Theta}} \hat{\varphi}_{Y H}-\frac{\left(\delta_{H} \lambda_{Y L}+\delta_{L} \lambda_{Y H}\right)}{\Delta_{\Theta} \Delta_{\Lambda}} \theta_{Y H} \hat{\varphi}_{Y H}, \\
\left.\hat{H}_{Y}\right|_{\hat{\varphi}_{Y H}>0}=\frac{\theta_{Y L} \theta_{Y H}}{\Delta_{\Theta}} \hat{\varphi}_{Y H}+\frac{\left(\delta_{H} \lambda_{X L}+\delta_{L} \lambda_{X H}\right)}{\Delta_{\Theta} \Delta_{\Lambda}} \theta_{Y H} \hat{\varphi}_{Y H}
\end{gathered}
$$

as the percentage change of high- and low-skilled employment in both industries. Again, if international outsourcing takes place in the relative low-skill intensive industry, employment in this industry unambiguously increases for high as well as for low-skilled labor. If international outsourcing takes place in the relative high-skill intensive industry, similar results occur. Proposition 3.4 summarizes the effects of international outsourcing on employment.

Proposition 3.4. With Cobb Douglas elasticities of substitution, effects on employment in all four international outsourcing scenarios are unambiguous and in line with the change in output. Since international outsourcing takes place, the outsourcing industry increases the employment of low-as well as high-skilled labor. The industry that remains integrated reduces the employment of both skill groups. This result supports the sector bias of international outsourcing since it depends on the relative skill intensity of the industry relocating production and not on the fragment being outsourced.

\section{Calibration Exercise}

While investigating the importance of the elasticity of substitution between low- and high-skilled labor for international outsourcing effects theoretically, results showed that, for output and employment, too many parameters have been at stake, squeezing us into a Cobb Douglas world. Thus, this section calibrates the model for a wider range of elasticities, by using data for the German economy in 2005 (provided by the German microcensus and the Genesis database of the German Federal Statistical Office) in order to constrain some parameter values. To illustrate the effects on relative wages, relative labor unit requirements, output, and employment, a one percent increase of international outsourcing is assumed.

To perform the calibration exercise, assumptions regarding the wages of high- and low-skilled labor, on the economy's high- and low-skilled labor endowment, and on the industries' skill intensity, are needed. Information on the gross wages for the high as well as the low skilled can be found in the Genesis database offered by the German Federal Statistical Office (Chapter 6.2 "wages and labor costs"). The data provides information on the gross wage per month for the German manufacturing and service industry in October 2005, disaggregated by skill level. Aggregating the skill groups into either high- or low-skilled labor and relating the monthly wage to the hours worked per month, we obtain an average gross wage of 20 euro per hour for lowskilled workers $\left(w_{L}\right)$ and 32 euro as average gross wage per hour for the high skilled $\left(w_{H}\right)$. (To aggregate the different skill groups, the definition of the (internationally comparable) "International Standard Classification of Education" (ISCED) from UNESCO (1997) is used. There, graduations from elementary school, secondary school, or junior high school (comparable with the German "Realschule") are regarded as low-skill education, whereas all higher education (grammar school, high school or university) is regarded as high skilled. We also calculated the numbers with respect to vocational training instead. However, results differ only marginally, not affecting the core of the results. To obtain the wage per hour we assume 140 hours of work per month.)

To obtain the overall labor endowment, we use data from the German microcensus 2005, offering information about the labor force grouped by age and education. Using the same aggregation procedure as above, we obtain an economy endowed with 25.3 million low-skilled workers and 10.9 million workers educated at a higher skill level.

Finally, parameters indicating the skill intensity of the two industries under consideration are needed. In these kinds of models, the industries' skill intensity is defined by the respective labor unit requirements. Since the requirement of low- and high-skilled labor depends on the production technology of each industry, these parameters are provided rarely by the empirical literature. For example, Krugman [23] calibrates a trade model focusing on a Northern economy and, therefore, assumes 50 percent skilled workers in the relative high-skill intensive industry and 20 percent in the relative low-skill intensive industry. (Krugman [23] bases his assumptions on Wood [24] and Balassa [25] who compute these numbers.) In this contribution, we follow Krugman [23] and assume that firms in the low-skill intensive industry require 1 hour of low-skilled $\left(a_{Y L}\right)$ and .2 hours of highskilled workers $\left(a_{Y H}\right)$ to produce one unit of commodity $Y$. The high-skill intensive $X$ industry needs 2 hours of lowskilled $\left(a_{X L}\right)$ and the same amount of high-skilled workers $\left(a_{X H}=2\right)$ to produce one unit. However, remember that only relative numbers matter. With respect to the sensitivity of the results, it is important to note that results are robust as long as we are able to distinguish between the industries' 
TABLE 4: Sector bias of international outsourcing (theoretical results).

\begin{tabular}{|c|c|c|c|c|}
\hline \multirow{2}{*}{ Scenario } & \multicolumn{2}{|c|}{ Low-skill intensive Industry } & \multicolumn{2}{|c|}{ High-skill intensive Industry } \\
\hline & Low-skill part & High-skill part & Low-skill part & High-skill part \\
\hline $\begin{array}{l}\text { Relative wages of the } \\
\text { high-skilled }\end{array}$ & $\downarrow$ & $\downarrow$ & $\uparrow$ & $\uparrow$ \\
\hline $\begin{array}{l}\text { Relative labor unit } \\
\text { requirements of the } \\
\text { high-skilled }\end{array}$ & $\uparrow$ & $\left(\sigma^{Y}>\Delta_{\Theta} / \theta_{X H}\right) \uparrow$ & $\left(\sigma^{X}>\Delta_{\Theta} / \theta_{Y L}\right) \downarrow$ & $\downarrow$ \\
\hline \multirow[t]{2}{*}{ Output } & $\begin{array}{l}\text { High-skill intensive } \\
\text { Industry } \downarrow\end{array}$ & $\begin{array}{c}\left(\sigma^{Y}=1\right) \\
\text { High-skill intensive } \\
\text { Industry } \downarrow\end{array}$ & $\begin{array}{l}\quad\left(\sigma^{X}=1\right) \\
\text { High-skill intensive } \\
\text { Industry } \uparrow\end{array}$ & $\begin{array}{l}\text { High-skill intensive } \\
\text { Industry } \uparrow\end{array}$ \\
\hline & $\begin{array}{l}\text { Low-skill intensive } \\
\text { Industry } \uparrow\end{array}$ & $\begin{array}{c}\text { Low-skill intensive } \\
\text { Industry } \uparrow \\
\left(\sigma^{Y}=1\right)\end{array}$ & $\begin{array}{c}\text { Low-skill intensive } \\
\text { Industry } \downarrow \\
\left(\sigma^{X}=1\right)\end{array}$ & $\begin{array}{l}\text { Low-skill intensive } \\
\text { Industry } \downarrow\end{array}$ \\
\hline \multirow[t]{2}{*}{ Employment } & $\begin{array}{l}\text { High-skill intensive } \\
\text { Industry } \downarrow\end{array}$ & $\begin{array}{l}\text { High-skill intensive } \\
\text { Industry } \downarrow\end{array}$ & $\begin{array}{l}\text { High-skill intensive } \\
\text { Industry } \uparrow\end{array}$ & $\begin{array}{l}\text { High-skill intensive } \\
\text { Industry } \uparrow\end{array}$ \\
\hline & $\begin{array}{l}\text { Low-skill intensive } \\
\text { Industry } \uparrow\end{array}$ & $\begin{array}{l}\text { Low-skill intensive } \\
\text { Industry } \uparrow\end{array}$ & $\begin{array}{c}\text { Low-skill intensive } \\
\text { Industry } \downarrow\end{array}$ & $\begin{array}{c}\text { Low-skill intensive } \\
\text { Industry } \downarrow\end{array}$ \\
\hline
\end{tabular}

relative skill intensity. As the calibration results in the next paragraphs show, unambiguous results will be achieved if we assume the numbers suggested by the empirical literature.

Based on these assumptions, we can calculate the price structure of the economy with $p=6.36$ as the relative price of the $X$ good in terms of $Y$.

4.1. Relative Wages. As shown in the theoretical section, effects of international outsourcing on relative wages are driven by the change in unit costs of the industry relocating production fragments. Since, as a direct effect, outsourcing reduces labor unit requirements, the effects seep through to relative wages. Calibrating the model with data for the German economy, we can support the existence of the wage effects of the sector bias. Table 3 summarizes the results.

Recall that if international outsourcing takes place in the relative low-skill intensive industry $(Y)$, relative wages of the high skilled decrease (see Figure 1 for a detailed explanation). If this industry increases the outsourcing of its low-skill intensive production block by one percent, relative wages of the high skilled decrease by 2.03 percent. If the industry increases the outsourcing of its high skill intensive production part by one percent, relative wages of the high-skilled decrease by .65 percent. By contrast, if international outsourcing takes place in the relative highskill intensive industry, the wage premium flows to the highskilled and thus increases their relative wages. If the highskill intensive industry expands outsourcing activities of its low-skill intensive production block by one percent, relative wages of the high-skilled increase by 1.03 percent. If the industry increases the outsourcing of its high-skill intensive fragment, the relative wage of the high skilled increases by 1.65 percent.

4.2. Relative Labor Unit Requirements. As for the effects of a one percent increase in international outsourcing activities on relative labor unit requirements of the high skilled, Figure 2 depicts the findings.

As the figure shows, if international outsourcing occurs in the relative low-skill intensive industry by relocating its low-skill intensive production block (scenario i: $\hat{\varphi}_{Y L}>0$ ), relative labor unit requirements of the high-skilled increase unambiguously in both industries, for each level of elasticity of substitution. A similar result occurs if international outsourcing takes place in the relative high-skill intensive industry by relocating its high-skill intensive production fragment (scenario iv: $\hat{\varphi}_{X H}>0$ ). There, relative labor unit requirements of the high skilled unambiguously decrease in both industries. These results occur since the wage effect outperforms the outsourcing effect in both cases. However, when turning to the two ambiguous scenarios (the two charts below), the outsourcing effect outperforms the wage effect for small values of the elasticity of substitution. If $\hat{\varphi}_{Y H}>0$ (scenario ii), relative labor unit requirements of the high skilled increase unambiguously in the $X$ industry, the industry that remains integrated, due to the decrease in relative high-skilled wages. In the relative low-skill intensive industry, in which the high-skill intensive production block gets outsourced, the outsourcing effect outperforms the wage effect if the elasticity of substitution is below the critical value of .61, leading to a decrease in relative high-skilled labor unit requirements. Thus, as shown by the theoretical results above, within a Cobb Douglas world, relative labor unit requirements of the high-skilled increase in any case. In scenario (iii: $\hat{\varphi}_{X L}>0$ ), a similar process occurs (in the opposite direction) and a critical value for the elasticity of substitution of 49 .

It is important to note that these numbers result from the specific numerical assumptions made above. Thus, the critical values .61 and .49 may change as the assumed numbers for labor unit requirements of the industries vary. However, concerning the robustness of the calibration exercise, the core of the results does not change as long as we 


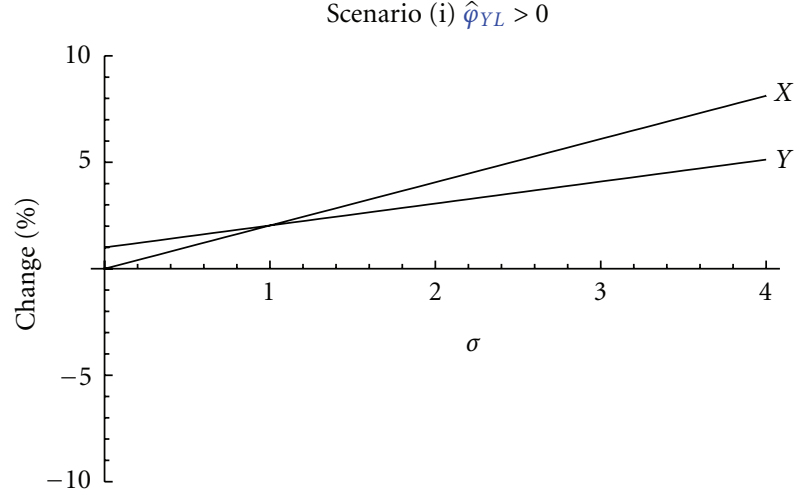

(a)

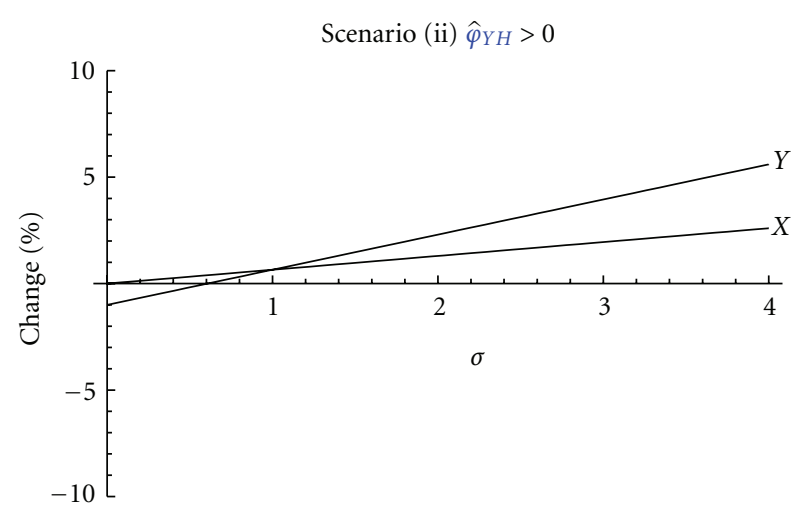

(c)

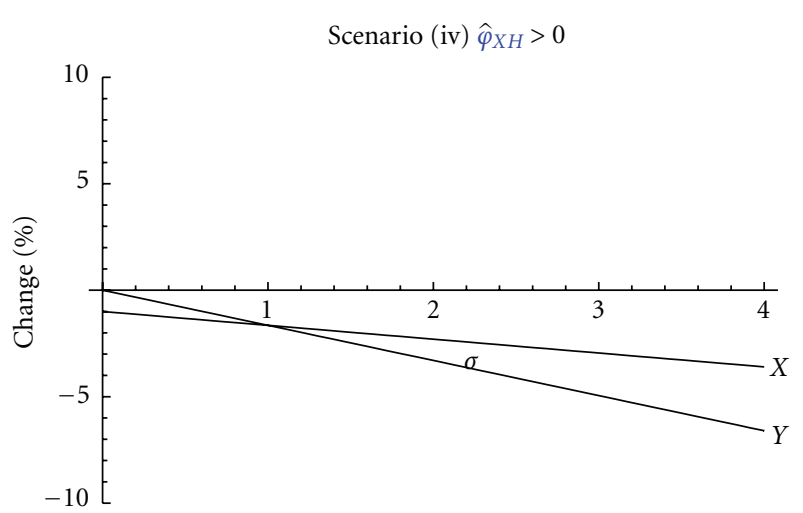

(b)

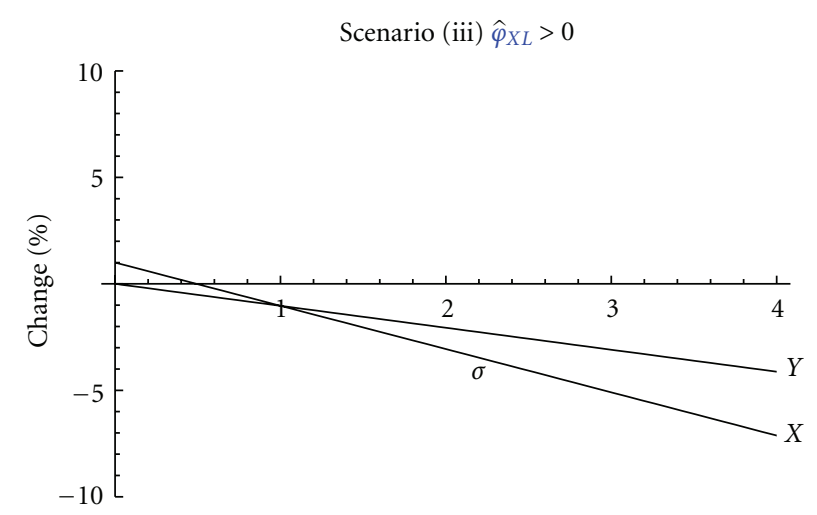

(d)

FIGURE 2: Effects on relative labor unit requirements of the high skilled.

are able to distinguish between the industries' relative skill intensity. In each such case, the critical values lie between 0 and 1 .

4.3. Output. Figure 3 depicts the effects of a one percent increase in international outsourcing activities on the output of the industries.

In the theoretical examination above, Cobb Douglas elasticities need to be assumed to handle the model. As German parameter values are assumed in this calibration exercise, we do not need to fix the elasticity and, thus, are able to achieve further insights. Similar to the effects on relative labor unit requirements, the effects on output are unambiguous in scenarios (i: $\hat{\varphi}_{Y L}>0$ ) and (iv: $\hat{\varphi}_{X H}>0$ ). The industry facing international outsourcing activities increases its output while the industry holding on to its integrated process decreases production. For the two ambiguous scenarios (ii: $\hat{\varphi}_{Y H}>0$ ) and (iii: $\hat{\varphi}_{X L}>0$ ), we obtain again that the industries' elasticity of substitution between high and low-skilled labor has to exceed a critical value. The critical value (scenario ii: .43 and scenario iii: .34) is in both cases smaller than unity. Thus, with elasticities exceeding these values, unambiguous results occur, confirming the sector bias of international outsourcing. The industry in which international outsourcing takes place expands production while the industry remaining integrated contracts.

Also with respect to output, the critical values change when altering the labor unit requirements of the industries. However, as already mentioned above, critical values lie between 0 and 1 as long as we are able to differ between the industries' relative skill intensity. Thus, within a Cobb Doulgas world, unambiguous results always emerge.

4.4. Employment. A similar picture emerges for the effects of international outsourcing on employment. Figure 4 depicts the results.

Since we examine the employment of low and highskilled labor in each of the two industries, four lines need to be considered in each chart of the figure. Again, in the two scenarios (i: $\hat{\varphi}_{Y L}>0$ ) and (iv: $\hat{\varphi}_{X H}>0$ ), unambiguous results occur. The industry relocating production abroad increases the employment of both skill groups, low- as well as high-skilled labor. By contrast, the industry holding on to its integrated production pattern has to reduce the employment of both skill groups. Considering the two ambiguous scenarios, unambiguous results can again only be achieved for elasticities of substitution above a critical value (scenario ii: .52 and scenario iii: .39). The critical value, however, is 


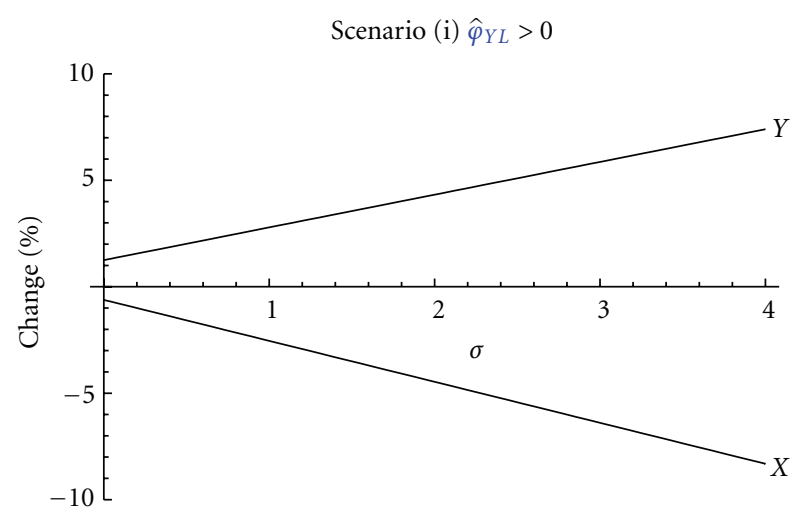

(a)

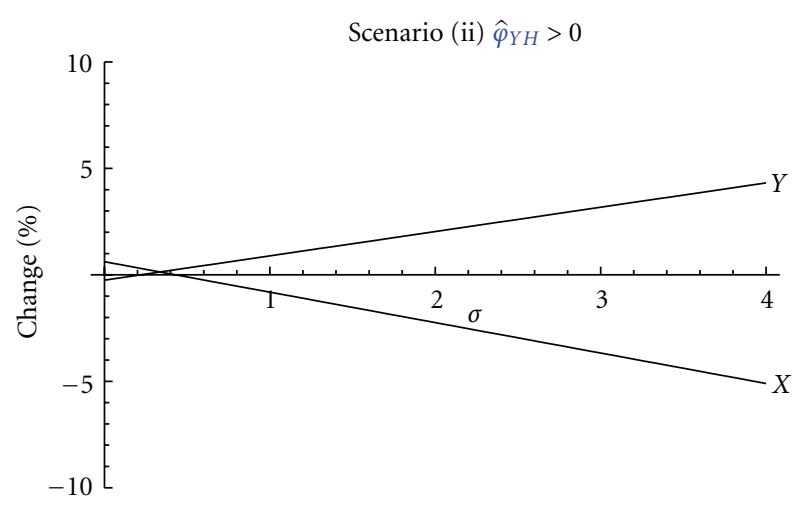

(c)

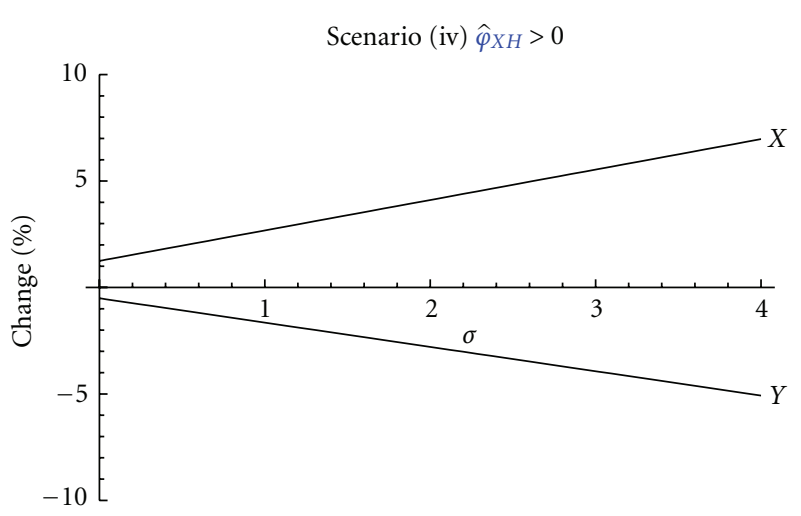

(b)

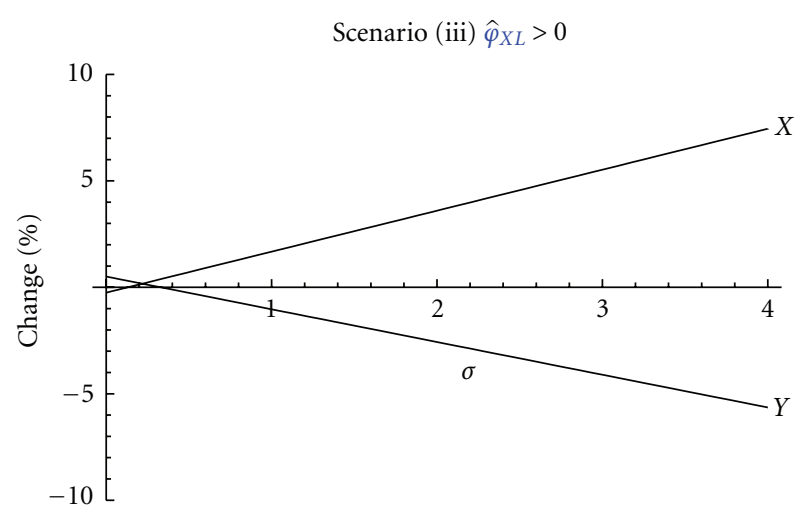

(d)

FIGURE 3: Effects on output.

in both scenarios beneath unity. With elasticities exceeding these values, the sector bias of international outsourcing can also be confirmed with respect to employment effects. The skill intensity of the industry relocating production matters, rather than which production block gets outsourced. With respect to the implications on employment, one has to consider that the results would depend crucially on specific labor market institutions. Especially in major European economies, like Germany, low-skilled unemployment is supposed to occur. This exercise, however, aims at calibrating the formal model shown above, and not at providing any empirical evidence for the German economy.

Also for the effects on employment, where the mechanics get more complex, calibration results are robust as long as we are able to distinguish between the relative skill intensity of the industries. Thus, with Cobb Douglas assumptions, results are unambiguously supporting the sector bias of international outsourcing.

\section{Conclusion}

As the sector bias of international outsourcing shows, lowskilled labor receives a wage premium and, thus, benefits, if outsourcing takes place in the relative low-skill intensive industry. If international outsourcing takes place in the relative high-skill intensive industry, the high-skilled benefit by receiving the wage markup. In general equilibrium, when examining the effects on labor unit requirements, output and employment, this wage effect gets accompanied by an outsourcing effect. Since the outsourcing effect can work in the opposite direction and even outperform the wage effect, results are only clear-cut in two out of four possible scenarios, either if the relative low-skill intensive industry relocates its low-skill intensive production fragment, or if the relative high-skill intensive industry relocates its high-skill intensive one. By contrast, if the relative low-skill intensive industry relocates its high-skill intensive production block, or the relative high-skill intensive industry its low-skill intensive one, international outsourcing effects are ambiguous. This incomplete picture may be one reason for the small number of empirical research investigating the sector bias of international outsourcing.

In this paper, general equilibrium effects of international outsourcing are analyzed within a formal model, using the modern duality approach in international trade theory, and calibrated with German microcensus data. As the results show, the elasticity of substitution between lowand high-skilled labor is the parameter at work completing the picture. With the elasticity exceeding a critical value (the value is beneath unity), the results on relative labor unit requirements, output and employment can be solved 


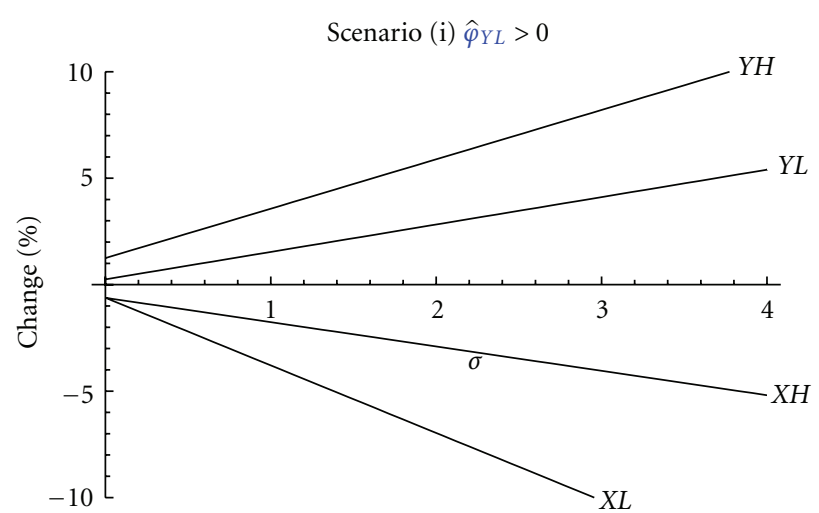

(a)

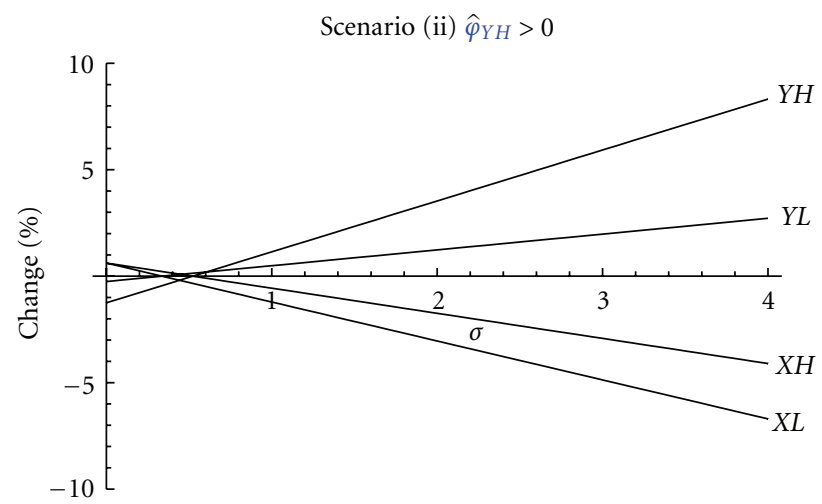

(c)

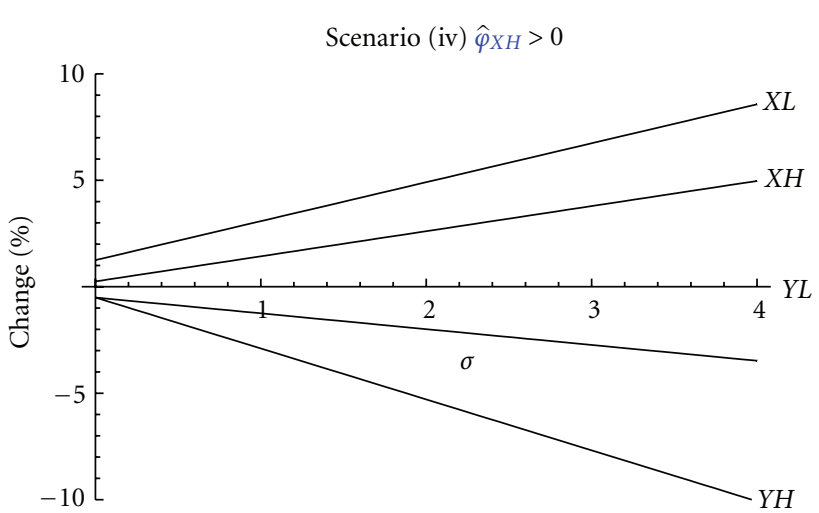

(b)

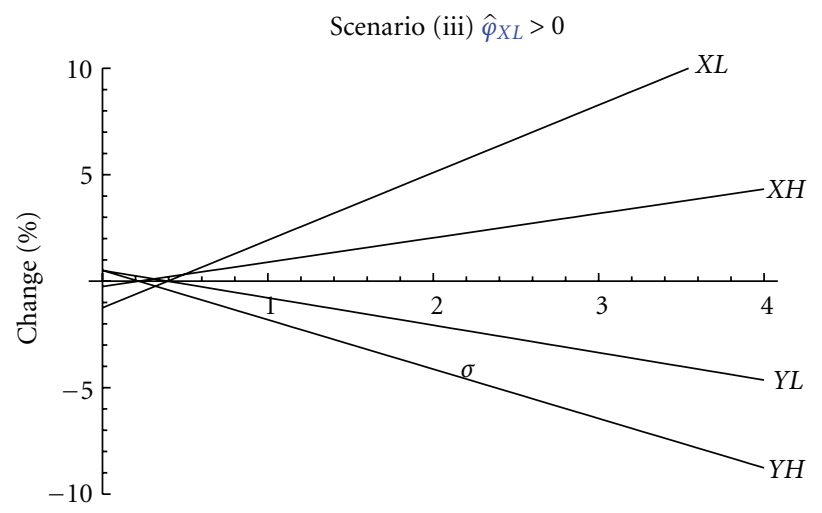

(d)

Figure 4: Effects on employment.

unambiguously, confirming the sector bias of international outsourcing. Provided that international outsourcing takes place in the relative low-skill intensive industry, relative wages of the low-skilled increase. In general equilibrium, this wage effect outperforms the outsourcing effect. Thus, both industries substitute high for low-skilled labor. As the relative low-skill intensive industry gets more competitive on world markets, relative output of this industry increases. This expansion induces labor flows of both skill groups toward the outsourcing industry. Reverse effects occur if international outsourcing takes place in the relative high-skill intensive industry. In both cases, the effects occur if the respective industry relocates either its low- or its high-skill intensive production fragment. Table 4 summarizes the formal results.

The findings are of high political importance as well. Completing the picture, unambiguous results can be achieved supporting the sector bias of international outsourcing. Cases in which outsourcing can be beneficial for low-skilled labor indeed do exist, even if it takes place in industrialized economies. Additionally, results may encourage empirical investigations examining the sector bias of international outsourcing. More evidence on the implications of international outsourcing occurring in industries that differ with respect to their skill intensity would be of high interest.

\section{References}

[1] G. Grossman and E. Helpman, "Outsourcing in a global economy," Review of Economic Studies, vol. 72, no. 1, pp. 135159, 2005.

[2] R. C. Feenstra and G. H. Hanson, "Foreign investment, outsourcing, and relative wages," in The Political Economy of Trade Policy, R. C. Feenstra, G. M. Grossman, and D. A. Irwin, Eds., pp. 89-127, MIT Press, Cambridge, Mass, USA, 1996.

[3] R. C. Feenstra and G. H. Hanson, "Globalization, outsourcing, and wage inequality," American Economic Review, vol. 86, no. 2, pp. 240-245, 1996.

[4] S. W. Arndt, "Globalization and the open economy," North American Journal of Economics and Finance, vol. 8, no. 1, pp. 71-79, 1997.

[5] S. W. Arndt, "Globalization and the gains from trade," in Trade, Growth, and Economic Policy in Open Economies, pp. 312, Springer, New York, NY, USA, 2008.

[6] S. W. Arndt, "Super-specialization and the gains from trade," Contemporary Economic Policy, vol. 16, no. 4, pp. 480-485, 1998.

[7] A. V. Deardorff, "Fragmentation across cones," in Fragmentation, New Production Patterns in the World Economy, S. W. Arndt and H. Kierzkowski, Eds., pp. 35-51, Oxford University Press, Oxford, UK, 2001.

[8] A. V. Deardorff, "Fragmentation in simple trade models," North American Journal of Economics and Finance, vol. 12, no. 2, pp. 121-137, 2001. 
[9] M. C. Burda and B. Dluhosch, "Cost competition, fragmentation, and globalization," Review of International Economics, vol. 10, no. 3, pp. 424-441, 2002.

[10] H. Egger and J. Falkinger, "The distributional effects of international outsourcing in a $2 \times 2$ production model," North American Journal of Economics and Finance, vol. 14, no. 2, pp. 189-206, 2003.

[11] W. Kohler, "The distributional effects of international fragmentation," German Economic Review, vol. 4, no. 1, pp. 89120, 2003.

[12] W. Kohler, "Offshoring: why do stories differ?" in The EU and Emerging Markets, G. Tondl, Ed., pp. 17-49, Springer, Vienna, Austria, 2009.

[13] G. M. Grossman and E. Rossi-Hansberg, "Trading tasks: a simple theory of offshoring," American Economic Review, vol. 98, no. 5, pp. 1978-1997, 2008.

[14] D. Horgos, "Labor market effects of international outsourcing: how measurement matters," International Review of Economics and Finance, vol. 18, no. 4, pp. 611-623, 2009.

[15] H. Uzawa, "Duality principles in the theory of cost and production," International Economic Review, vol. 5, no. 2, pp. 216-220, 1964.

[16] W. E. Diewert, "An application of the shephard duality theorem: a generalized Leontief production function," Journal of Political Economy, vol. 79, pp. 481-507, 1971.

[17] W. E. Diewert, "Applications of duality theory," in Frontiers of Quantitative Economics, Vol. 2, M. D. Intriligator and D. A. Kendrick, Eds., pp. 106-171, North-Holland, Amsterdam, The Netherlands, 1974.

[18] A. D. Woodland, "A dual approach to equilibrium in the production sector in international trade theory," Canadian Journal of Economics, vol. 5, no. 1, pp. 50-68, 1977.

[19] M. Mussa, "The two-sector model in terms of its dual: a geometric exposition," Journal of International Economics, vol. 9, no. 4, pp. 513-526, 1979.

[20] R. W. Jones, "The structure of simple general equilibrium models," Journal of Political Economy, vol. 73, no. 6, pp. 557$572,1965$.

[21] A. P. Lerner, "The diagrammatical representation of cost conditions in international trade," Economica, vol. 12, pp. 346$356,1932$.

[22] J. S. Chipman, "A survey of the theory of international trade: part 3, the modern economy," Econometrica, vol. 34, pp. 18 76, 1966.

[23] P. R. Krugman, "Growing world trade: causes and consequences," Brookings Papers on Economic Activity, vol. 1, no. 1, pp. 327-362, 1995.

[24] A. Wood, North-South Trade, Employment and Inequality: Changing Fortunes in a Skill Driven World, Clarendon Press, New York, NY, USA, 1994.

[25] B. Balassa, "The changing international division of labor in manufactured goods," Banca Nazionale del Lavoro Quarterly Review, vol. 130, pp. 243-285, 1979. 


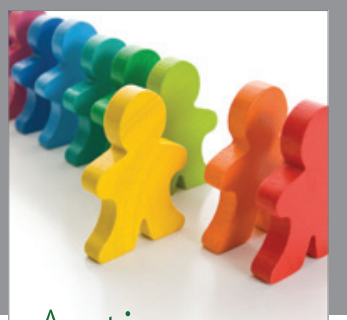

Autism

Research and Treatment
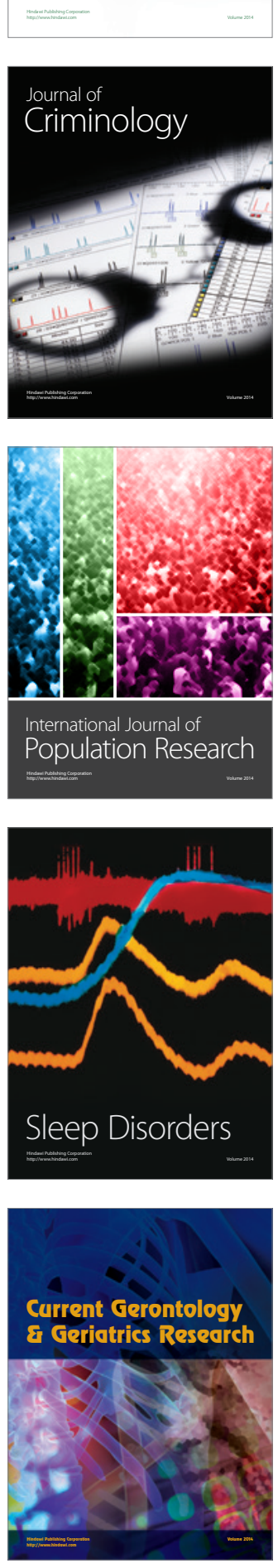
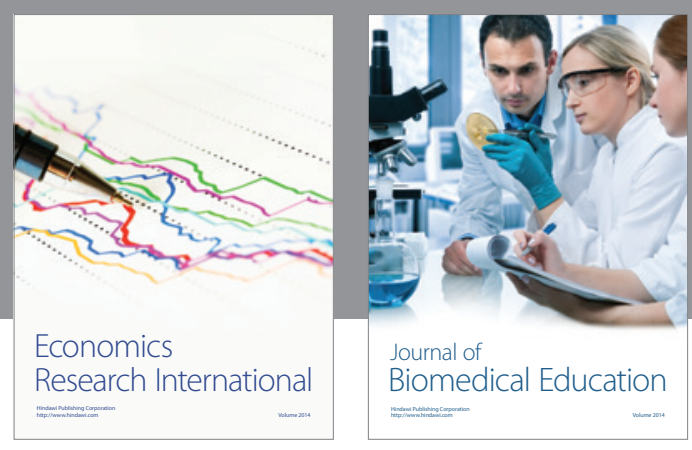

Journal of

Biomedical Education

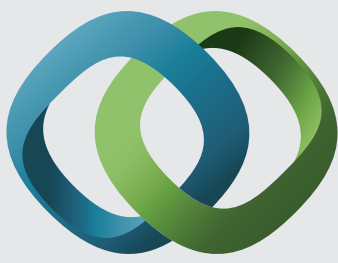

\section{Hindawi}

Submit your manuscripts at

http://www.hindawi.com
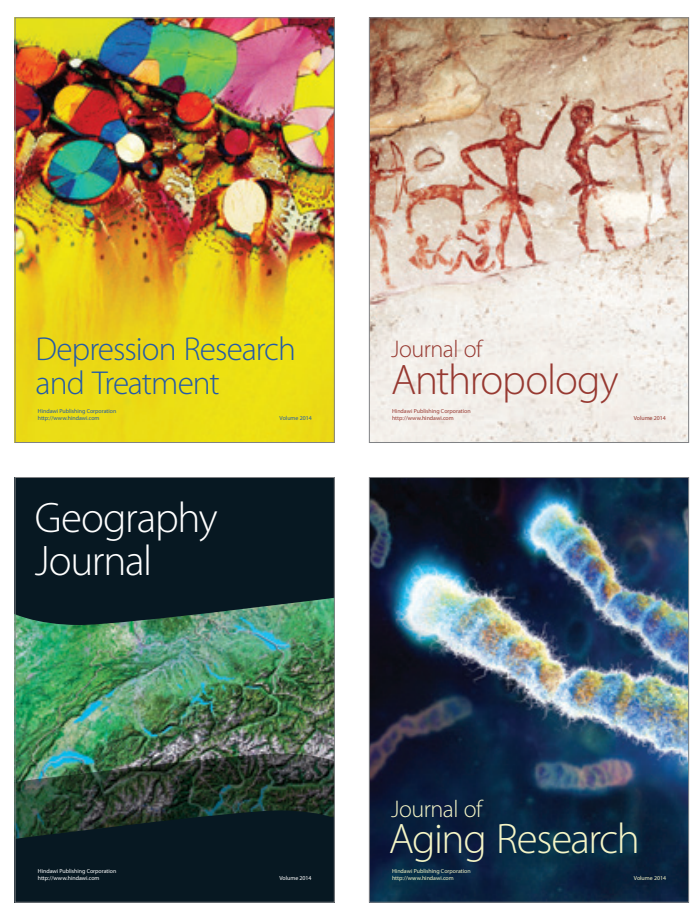

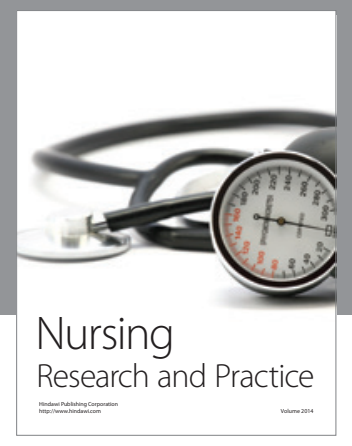

Nursing

Research and Practice

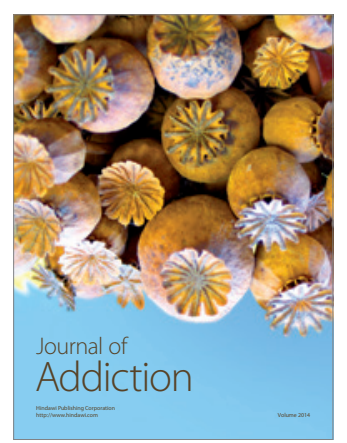

Child Development

Research

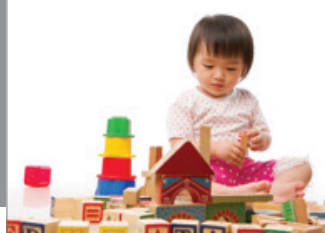

迥
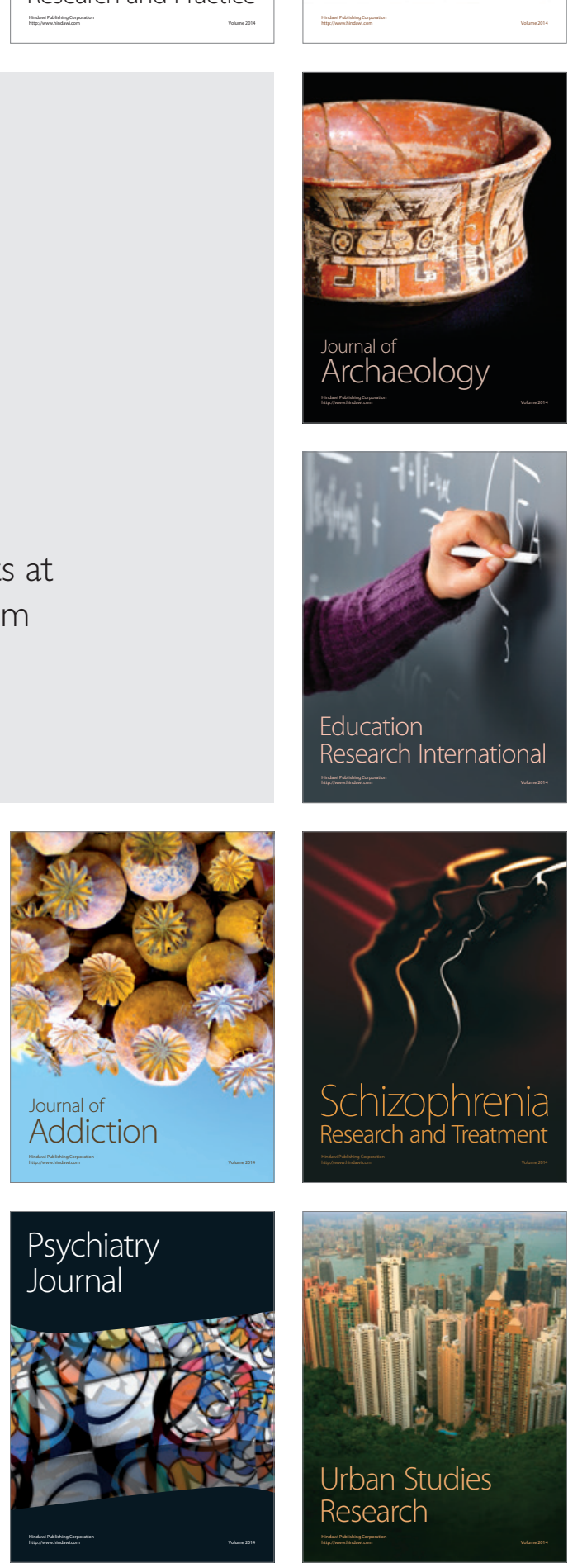